\title{
Shared Extended-Spectrum $\beta$-Lactamase-Producing Salmonella Serovars between Agricultural and Aquatic Environments Revealed through invA Amplicon Sequencing
}

\author{
Cecilia Mahlatse Raseala, Mutshiene Deogratias Ekwanzala and \\ Maggy Ndombo Benteke Momba * (D)
}

Department of Environmental, Water and Earth Sciences, Arcadia Campus, Tshwane University of Technology, Private BagX680, Pretoria 0001, South Africa; ceciliamahlatse5@gmail.com (C.M.R.); ekwanzala.md@gmail.com (M.D.E.)

* Correspondence: mombamnb@tut.ac.za; Tel.: +27-12-382-6365

Received: 29 October 2020; Accepted: 11 November 2020; Published: 30 November 2020

check for updates

\begin{abstract}
The presence of antibiotic-resistant Salmonella spp. in the environment is of great public health interest, worldwide. Furthermore, its extended-spectrum $\beta$-lactamase (ESBL)-producing strains constitute an emerging global health concern due to their limited treatment options in hospital. Therefore, this study aimed at characterising and tracking nonresistant and ESBL-producing Salmonella spp. from agricultural settings to nearby water sources highlighting their antibiotic resistance genes (ARG) and virulence factor (VF) distribution using a combination of both culture-dependent and independent methods. Furthermore, this study investigated the diversity and shared serovars among sampled matrices using amplicon sequencing of the invasion gene A (inv $A$ ) of Salmonella spp. The results showed that soil had the highest prevalence of Salmonella spp. (62.5\%, 65/104) and ESBL-producing Salmonella (34.6\%,36/104). For typed ARG, the most commonly detected gene was bla $a_{\mathrm{OXA}}$ with $75 \%$ (30/40), followed by bla $a_{\mathrm{CTX}-\mathrm{M}} 67.5 \%(27 / 40)$, bla $30 \%(12 / 40)$ gene; bla $\mathrm{SHV}$ gene was not detected in isolated ESBL-producing Salmonella spp. For VF, the most detected gene was inv A $(96.9 \%, 38 / 40)$, followed by spaM $(17.5 \%, 7 / 40)$, spiC $(40 \%, 16 / 40)$, orf $\mathrm{L}(32.5 \%, 13 / 40)$, mis L 32.5\% (13/40) and pipD 32.5 (13/40). For diversity analysis, soil, manure, irrigation water and nearby freshwater revealed 81, 68, 12 and 9 serovars, respectively. Soil, manure, irrigation water and freshwater stream samples shared five serovars, which indicated circulation of ESBL-producing Salmonella spp. within the agricultural environment and nearby water sources. Soil is therefore identified as one of the major reservoirs of ESBL-producing Salmonella spp. It is concluded that agricultural environment contamination may have a direct relationship with the presence of antibiotic-producing Salmonella in freshwater streams.
\end{abstract}

Keywords: extended-spectrum beta-lactamases; Salmonella spp.; agricultural environment; water

\section{Introduction}

Salmonella spp. are a member of the Enterobacteriaceae family, and consist of two main species, namely S. enterica and S. bongori. Of the two species, S. enterica, has been reported to comprise more than 2500 serovars [1], which are separated based on their differences in lipopolysaccharide layer with regard to their somatic $(\mathrm{O})$ and flagellar $(\mathrm{H})$ antigens [2]. These serovars are the most critical foodborne and waterborne pathogens, causing thousands of hospitalisations and deaths worldwide. According to Stanaway et al. [3], nontyphoidal Salmonella spp. was linked to 535,000 infection cases worldwide with the highest incidence from subSaharan Africa (34.5\%) and children under the age of 
five (34.3\%) were the most affected. In the United States, for example, Salmonella spp. outbreak was reported in 40 states where the consumption of imported Mexican cucumbers caused illness in at least 907 people, with six deaths from July 2015 to February 2016 [4]. In South Africa, the Enteric Diseases Centre of the National Institute for Communicable Diseases reported a Salmonella spp. outbreak with approximately 4966 cases associated with food- and waterborne diseases between 2003 and 2005 [5].

It has been recorded that Salmonella spp. can be transmitted through water, food, soil or person-to-person contact [1]. Nevertheless, contaminated fresh produce and raw meat are well-known as the primary vehicles for Salmonella spp. transmission to humans [6-8]. This pathogen can also be spread through the faecal-oral route of contamination where the animal or human faeces enter the aquatic environment, such as rivers, directly from agricultural land through runoff [9]. It has been reported that Salmonella spp. can persist for an extended time in soil, water and faeces excreted in the environment [1]. This situation is particularly a matter of concern in low- and middle-income countries (LMICs), where surface water is used for domestic purposes. Poor water quality has continuously led to the world burden of waterborne infections [10]. Furthermore, poor sanitation and inadequate potable water supply make contributions to the increase in enteric fever and diarrhoea [11], leading to an everlasting prevalence of water-related infectious agents attributed to this water source. This situation is amplified by the recent emergence of antibiotic-resistant Salmonella spp. strains.

The development of antibiotic resistance (AR) is thought to arise from the release of antibiotics into environmental settings [12] such as agricultural and farming environments. It has been reported that approximately $70 \%$ of antibiotics produced are used for animal prophylaxis and as growth promoters [13]. This overuse and misuse of antibiotics in animal farming have impacted the quality of animal manure applied to agricultural soil. Moreover, there is an increasing reliance on wastewater for irrigation, which also disperses resistant bacteria from wastewater to nearby freshwater [14].

Salmonella spp., like other bacteria in the Enterobacteriaceae family, have become resistant to antibiotics previously effective in treating the same infections. The emergence of multidrug-resistant Salmonella spp. has been reported worldwide [15]. Parisi et al. [15] reported that multidrug serovars are mostly related to Typhimurium, Enteritidis, Newport and Heidelberg. Furthermore, infections brought by AR Salmonella spp. have been reported to be associated with excess bloodstream infections and higher mortality compared to their pansusceptible strains [15]. Of these resistant strains, there are extended-spectrum $\beta$-lactamases (ESBL)-producing Salmonella spp. In 2017, ESBL-producing Enterobacteriaceae family, which Salmonella spp. belong to, was set as a high priority organism for research and new antibiotic development [16]. A more severe case of ESBL called carbapenem resistance is thought to have developed during ertapenem treatment of ceftriaxone-resistant and ciprofloxacin-resistant Salmonella enterica serotype Typhimurium [17]. The emergence and spread of ESBL production among isolates of Enterobacteriaceae, both from community and healthcare settings, have engendered fear. Several $\beta$-lactamase enzymes such as TEM, SHV, CTX-M and OXA have been observed in Salmonella serovars from all over the world. Extended-spectrum $\beta$-lactamases have negatively impacted clinical outcomes, resulting in expensive treatment options [18]. Fewer strategies have been proposed to address the contributions of animal and environmental reservoirs to the dissemination of antibiotic resistance in LMICs.

Surveillance and serotyping of Salmonella have been conducted worldwide [19], and several studies carried out have documented the direct transfer of antibiotic-resistant bacteria from animals to humans. Molecular techniques such as polymerase chain reaction (PCR), restriction fragment length polymorphism (RFLP), sequencing of $\mathrm{H}$ antigen genes ( $f l i \mathrm{C}$ and $f l j B$ ), multiplex PCR of the O-antigen encoding genes (tyv and $w z x)$, phylogenetic analyses of the beta subunit of ATP synthase gene $(a t p D)$ and automated ribotyping system, 16S-23S rRNA spacer have been developed for typing Salmonella serovars. However, their discriminative ability is insufficient for practical applications [19]. Most studies have reported the dissemination of ESBL-producing Salmonella spp. from agricultural environments [20-22], and only a few of them have focussed on ESBL-producing Salmonella spp. Limited investigation on 
ESBL production in agricultural environments could be due to low concentrations of ESBL-producing bacteria in these environments compared to clinical settings.

Consequently, this study aimed at characterising and tracking the prevalence of Salmonella spp. versus ESBL-producing Salmonella spp. in agricultural and aquatic environments as well as their antibiotic resistance genes and virulence gene distribution. Furthermore, this study investigated the diversity and shared serovars among sampled matrices using amplicon sequencing of the inv $A$ gene of Salmonella spp.

\section{Materials and Methods}

\subsection{Study Site Description and Sample Collection}

The study site and sample collection are described in detail by Raseala et al. [23].

\subsection{Media and Sample Preparation}

All media were prepared according to the manufacturers' instructions. CHROMagar ${ }^{\mathrm{TM}}$ Salmonella Plus media and CHROMagar ${ }^{\mathrm{TM}}$ Salmonella Plus media supplemented with ESBL supplement (Media Mage, Johannesburg, South Africa) were used for the isolation of Salmonella spp. and ESBL-producing Salmonella spp., respectively.

Sample collection and preparation was performed as described by Raseala et al. [23].

\subsection{Detection and Isolation of ESBL-Producing Salmonella spp. and Salmonella spp.}

For the detection and isolation of Salmonella, a loopful of the overnight suspension in tryptic soy broth was streaked using a streaking loop on ESBL-supplemented and unsupplemented CHROMagar ${ }^{\mathrm{TM}}$ Salmonella Plus media to detect and isolate non-ESBL-producing Salmonella spp. and ESBL- producing Salmonella spp., respectively. The positive controls Salmonella Typhimurium ATCC 14028 (ThermoFisher Scientific, Johannesburg, South Africa) and Salmonella enterica subsp. enterica serovar Typhimurium strain ATCC 13311 (ThermoFisher Scientific) were used as quality control cultures for the isolation of Salmonella spp. and ESBL-producing Salmonella isolates. The plates were incubated at $37^{\circ} \mathrm{C}$ for 18 to $24 \mathrm{~h}$, and samples were analysed in triplicate.

To obtain pure cultures for serotyping, antibiotic-resistant gene (ARG) and virulence factor (VF) detection, typical growth colonies on Petri dishes were randomly selected and subcultured again on CHROMagar ${ }^{\text {TM }}$ Salmonella Plus media supplemented with ESBL supplement and incubated at $37^{\circ} \mathrm{C}$ for 18 to $24 \mathrm{~h}$. Furthermore, the grown colonies were streaked on tryptic soy agar (Sigma-Aldrich, Johannesburg, South Africa) and incubated for $24 \mathrm{~h}$ at $37^{\circ} \mathrm{C}$. For invA amplicon analysis, all typical colonies of ESBL-producing Salmonella spp. were collected, transferred to sterile microcentrifuge tubes, and preserved in $15 \%$ glycerol at $-20^{\circ} \mathrm{C}$ until further analyses.

\subsection{Bacterial Confirmation and Identification}

To confirm and identify the presumptive isolated ESBL-producing Salmonella spp., immunological lateral flow test Singlepath ${ }^{\circledR}$ Salmonella (Merck, Johannesburg, South Africa) test kit and matrix-assisted laser desorption/ionisation-time of flight mass spectrometry (Bruker Daltonik MALDI Biotyper, Billerica, MA, USA) analysis were performed as described by Raseala et al. [23], respectively. Only ESBL-producing Salmonella spp. isolates that showed positive reactions on the Singlepath ${ }^{\circledR}$ Salmonella kit were further sent for identification at the MALDI-TOF diagnostic service of the University of Pretoria for identification using MALDI-TOF MS. Data acquisition from the machine was acquired through the MBT Explorer Software plus MBT Compass Library.

\subsection{Serogrouping of ESBL-Producing Salmonella spp. Isolates}

The identified ESBL-producing Salmonella spp. were serogrouped using a Wellcolex colour Salmonella test kit (Thermo Scientific) following the manufacturer's instructions. Positive controls 
with the positive control reagents (green, blue and red controls) were carried out alongside the latex reagents 1 and 2 separately without inoculums. Results were interpreted according to the manufacturer's guidelines.

\subsection{DNA Extraction}

For the molecular study, the genomic DNA from ESBL-producing Salmonella spp. was extracted using the InstaGene ${ }^{\mathrm{TM}}$ matrix (Bio-Rad, Johannesburg, South Africa) according to the manufacturer's instructions as detailed by Raseala et al. [23].

For the invA amplicon sequencing analysis, all suspected ESBL-producing Salmonella spp. isolates grown on ESBL-supplemented CHROMagar ${ }^{\mathrm{TM}}$ Salmonella Plus plates were pooled together per sample source and transferred into a DNase-free Eppendorf tube. These bacterial cells were disrupted in a $2 \mathrm{~mL}$ microfuge tube containing $1.5 \mathrm{~mL}$ of $1 \times$ PBS and 2\% Tween 20 (Sigma Aldrich, South Africa) using a Disruptor Genie ${ }^{\circledR}$ Vortex mixer (Scientific Industries Inc., NY, USA). Each microfuge tube containing bacterial cells was placed under centrifugation at 10,000 $\times$ rpm for $5 \mathrm{~min}$, and the resulting bacterial pellet was used to extract genomic DNA using a ZymoBIOMICS ${ }^{\mathrm{TM}}$ DNA Miniprep Kit (Zymo Research, Irvine, CA, USA) according to the manufacturer's instructions.

\subsection{Detection of ARG in ESBL-Producing Salmonella spp. Using PCR}

Five different $\mathrm{ARG}$, namely $b \operatorname{la}_{\mathrm{CTX}}, b a_{\mathrm{TEM}}, b l a_{\mathrm{OXA}}, b l a_{\mathrm{SHV}}$ and sul1, were assessed in 40 randomly selected ESBL-producing Salmonella spp. isolates (10 from each matrix). The selected ARG were amplified by PCR using the primers listed in Table 1. Each reaction mixture consisted of $10 \mathrm{~mL}$ of SsoAdvanced Evergreen Supermix, $2 \mu \mathrm{L}$ of each primer (reverse and forward), $5 \mu \mathrm{L}$ of the DNA template and $3 \mu \mathrm{L}$ of nuclease-free water, resulting in a final volume of $20 \mu \mathrm{L}$ per reaction. The primers were prepared according to the manufacturer's instructions (Inqaba Biotec, Pretoria, South Africa) to obtain stocks at working concentrations of each of the PCR primer. The CFX96 Touch $^{\mathrm{TM}}$ real-time PCR detection system (Bio-Rad, South Africa) was used for PCR assays using the following conditions: initial denaturation at $98^{\circ} \mathrm{C}$ for $2 \mathrm{~min}$, followed by 40 cycles of amplification of denaturation $98^{\circ} \mathrm{C}$ for $5 \mathrm{~s}$, annealing for $30 \mathrm{~s}\left(60^{\circ} \mathrm{C}\right.$ for bla $a_{\mathrm{CTX}}, 50^{\circ} \mathrm{C}$ for bla $\mathrm{SHV}, 58{ }^{\circ} \mathrm{C}$ for bla $a_{\mathrm{OXA}}, 53^{\circ} \mathrm{C}$ for $b l a_{\mathrm{TEM}}$ and $65^{\circ} \mathrm{C}$ for sul 1 genes) and a primer extension at $72{ }^{\circ} \mathrm{C}$ for $5 \mathrm{~s}$. Bio-Rad CFX Manager software (ver. 3.0) was used to acquire the generated data. The amplicon sizes were checked by running the amplicons on a $1 \%$ agarose gel (ThermoFisher, South Africa) stained with ethidium bromide (ThermoFisher, South Africa) and then visualised under a UV transilluminator (InGenius Bio Imaging System, Syngene, Cambridge, UK).

\subsection{Detection of VF in ESBL-Producing Salmonella spp. Using PCR}

Polymerase chain reactions were performed on the same 40 DNA extracts selected for detection of ARG and analysed for five virulence genes (spa $\mathrm{M}$, orf $\mathrm{L}, s p i \mathrm{C}$, mis $\mathrm{L}$ and $p i p \mathrm{D})$. The PCR primers used to amplify internal fragments from the genes mentioned above are shown in Table 1. Amplifications were carried out using the same reaction mixture used to screen ARG. The hot start technique used to prevent nonspecific amplification of the virulence genes was as follows: initial enzyme activation at $98^{\circ} \mathrm{C}$ for $2 \mathrm{~min}$, followed by 40 amplification cycles of denaturation at $98^{\circ} \mathrm{C}$ for $5 \mathrm{~s}$, annealing (spiC gene at $54^{\circ} \mathrm{C}$, misL and orf $\mathrm{L}$ at $58^{\circ} \mathrm{C}$, spaM $55^{\circ} \mathrm{C}$ and pipD gene at $55^{\circ} \mathrm{C}$ ) and a final extension at $72{ }^{\circ} \mathrm{C}$ for 6 min.

For the amplicon sequencing analysis targeting the invA gene, the CFX96 ${ }^{\mathrm{TM}}$ Real-time PCR Detection System (Bio-Rad, South Africa) was used for PCR assays. The following cycling parameters were used: initial denaturation at $98^{\circ} \mathrm{C}$ for $2 \mathrm{~min}$, following 40 cycles of amplification, denaturation at $98^{\circ} \mathrm{C}$ for $5 \mathrm{~s}$, annealing at $58^{\circ} \mathrm{C}$ each for $30 \mathrm{~s}$, extension at $72{ }^{\circ} \mathrm{C}$ for $1 \mathrm{~min}$ and a single final extension at $72{ }^{\circ} \mathrm{C}$ for $2 \mathrm{~min}$. The amplicon sizes were checked by running the samples on a $1 \%$ agarose gel (ThermoFisher, South Africa) stained with ethidium bromide (ThermoFisher, South Africa) and then visualised under a UV transilluminator (InGenius Bio Imaging System, Syngene, Cambridge, UK). The digital image of the band patterns was acquired and viewed with UV light to determine the 
presence of the PCR products. The PCR products were sent for next-generation sequencing at Inqaba Biotechnology Industries (Pretoria, South Africa).

Table 1. Oligonucleotide primers in the PCR assay.

\begin{tabular}{|c|c|c|c|c|}
\hline Genes & Nucleotide Sequences $\left(5^{\prime}-3^{\prime}\right)$ & Target Size & $T_{\text {Annealing }}\left({ }^{\circ} \mathrm{C}\right)$ & Reference \\
\hline \multicolumn{5}{|c|}{ Salmonella spp. ARG } \\
\hline$b l a_{\mathrm{CTX}}$ & $\begin{array}{l}\text { F:ATGTGCAGYACCAGTAARGTKATGGC } \\
\text { R:TGGGTRAARTARGTSACCAGAAYCAGCGG }\end{array}$ & 593 & 60 & {$[24]$} \\
\hline$b l a_{\mathrm{SHV}}$ & $\begin{array}{l}\text { F:TTCGCCTGTGTATTATCTCCCTG } \\
\text { R:TTAGCGTTGCCAGTGYTCG }\end{array}$ & 854 & 50 & {$[24]$} \\
\hline bla $\mathrm{OXA}-1$ & $\begin{array}{c}\text { F:ATGAAAAACACAATACATATCAACTTCGC } \\
\text { R:GTGTGTTTAGAATGGTGATCGCATT }\end{array}$ & 820 & 58 & {$[24]$} \\
\hline sul1 & $\begin{array}{c}\text { F:GCGCGGCGTGGGCTACCT } \\
\text { R:GATTTCCGCGACACCGAGACAA }\end{array}$ & 350 & 65 & [25] \\
\hline$b l a_{\mathrm{TEM}}$ & $\begin{array}{l}\text { F:ATGAGTATTCAACATTTCCG } \\
\text { R:ACCAATGCTTAATCAGTGAG }\end{array}$ & 859 & 53 & [26] \\
\hline \multicolumn{5}{|c|}{ Salmonella spp. VF } \\
\hline spiC & $\begin{array}{l}\text { F:CCTGGATAATGACTATTGAT } \\
\text { R:AGTTTATGGTGATTGCGTAT }\end{array}$ & 309 & 54 & [27] \\
\hline misL & $\begin{array}{l}\text { F:GTCGGCGAATGCCGCGAATA } \\
\text { R:GCGCTGTTAACGCTAATAGT }\end{array}$ & 400 & 58 & {$[27]$} \\
\hline pip D & $\begin{array}{l}\text { F:CGGCGATTCATGACTTTGAT } \\
\text { R:CGTTATCATTCGGATCGTAA }\end{array}$ & 350 & 56 & [27] \\
\hline spaM & $\begin{array}{l}\text { F:CGCTGTACGGTATTTCATT } \\
\text { R:CTGACTCGGCCTCTTCCTG }\end{array}$ & 394 & 55 & [28] \\
\hline $\operatorname{orf} \mathrm{L}$ & $\begin{array}{l}\text { F:GGAGTATCGATAAAGATGTT } \\
\text { R:GCGCGTAACGTCAGAATCAA }\end{array}$ & 550 & 58 & [27] \\
\hline inv A & $\begin{array}{c}\text { F:GTGAAATTATCGCCACGTTCGGGCAA } \\
\text { R:TCATCGCACCGTCAAAGGAACC }\end{array}$ & 284 & 45 & {$[28]$} \\
\hline
\end{tabular}

\subsection{InvA Amplicon Sequencing and Analysis}

The invA gene has been widely used to reveal Salmonella spp. diversity in numerous studies [29,30] with the ability to show up to 86 serovars [31]. Amplicon sequencing was carried out on invA gene PCR products at the sequencing centre using an Illumina MiSeq device (Illumina Inc., San Diego, CA, USA), following the manufacturer's instructions.

\subsection{Bioinformatic Analysis of the invA Sequences}

Quality control and improvements of raw sequences from the sequencer were performed in Galaxy (usegalaxy.org). Briefly, raw reads were imported into the galaxy server. Since paired-end reads were generated, each matrix (irrigation water, soil, manure and nearby freshwater stream) consisted of two separate fastq files, one containing the forward reads, and the other the reverse reads. Using the FASTQ join v.1.1.2-801.1 function [32] in Galaxy, the forward and reverse read generated eight joined samples, namely IW1, IW2, S1, S2, M1, M2, WB1 and WB2. The quality of generated files was assessed using FastQC v.0.72+galaxy1 software [33]. To obtain high-quality sequences for downstream analysis, trimming of low-quality bases and removal of adapters were performed using Trimmomatic v.0.38.0 [34], PRINSEQ v.0.20.4 [35], Trim Galore! v.0.6.3 [36], Fastp v.0.19.5+galaxy1 [37]. All pipelines were run in default settings as set in the Galaxy server. Chimaera removal was performed using UCHIME, according to the de novo method [38]. Removal of human DNA contamination was performed using DeconSeq v.0.4.3 [39]. Generated high-quality sequence reads were then submitted to the Kaiju online web server [40] to obtain the Salmonella spp. serovars hit using RefSeq Genomes (proteins from completely assembled RefSeq genomes-bacteria, archaea and viruses) as the reference database (defaults parameters of ticked SEG filter, the Run mode in Greedy (minimum match score of 75 and 5 allowed mismatches) with a minimum match length of 11). 


\subsection{Data Analysis}

Matrix prevalence was expressed as the percentage of positive samples over the total number of samples tested. Differences in the prevalence of ESBL-producing Salmonella between the four matrices were assessed using the chi-square test ( $\chi^{2}$ test). Salmonella spp. serovars richness and Shannon-Wiener $\left(\mathrm{H}^{\prime}\right)$ diversities in samples were determined using the vegan $\mathrm{R}$ package in Microsoft R Open 3.3.2. One-way ANOVA with a Tukey's HSD post-hoc test was performed to reveal significant differences among diversity mean across assessed matrices. The analysis was performed at a $95 \%$ confidence limit $(p \leq 0.05)$. Graphs were constructed using the ggplot2 package in Microsoft R Open 3.3.2.

\section{Results}

\subsection{Prevalence of Nonresistant and ESBL-Producing Salmonella spp.}

In total, 104 samples were collected over thirteen weeks, starting from June 2018 to September 2018, which consisted of 26 individual samples for each matrix (soil, manure, irrigation water and freshwater stream). Once transported to the laboratory, each sample was subdivided into four technical replicates before analysis, making a total of 416 technical replicates to avoid errors. Of the 416 samples, 53.6\% (223/416) samples produced presumptive colonies on unsupplemented CHROMagar ${ }^{\mathrm{TM}}$ Salmonella Plus media, whereas ESBL-supplemented CHROMagar ${ }^{\mathrm{TM}}$ Salmonella Plus media showed a 23.6\% (98/416) of the presumptive ESBL-producing Salmonella spp. The prevalence of each positive sample for Salmonella spp. versus ESBL-producing Salmonella spp. per matrix is shown in Figure 1. Overall, both agricultural settings and nearby freshwater harboured Salmonella spp. and ESBL-producing Salmonella spp. The highest number of presumptive Salmonella spp. was found in soil with $62.5 \%$ (65/104), followed by manure with 56.731\% (59/104), irrigation water 50\% (52/104) and lastly freshwater with 45.192\% (47/104). In terms of ESBL-producing Salmonella spp., the highest incidence of presumptive ESBL-producing Salmonella was also found in soil samples with 34.615\% (36/104), followed by manure samples $24.038 \%$ (25/104) and irrigation water 21.153\% (22/104) and the lowest was found in freshwater stream samples with $14.423 \%$ (15/104). Statistically, $p$-values through the $\chi^{2}$ test revealed a significant difference $(p \leq 0.05)$ between total Salmonella spp. and ESBL-producing Salmonella of the same matrix. Furthermore, $p$-values of ESBL-producing prevalence between was significantly different $(p \leq 0.05)$ for the following matrices soil-manure, soil-irrigation water, soil-nearby water, manure-nearby water and irrigation-water-nearby water, However, no statistically different prevalence were observed for ESBL-producing Salmonella spp. between manure-irrigation water $(p=0.224)$.

\subsection{Bacterial Confirmation and Identification}

Only ESBL-producing Salmonella isolates that showed a positive reaction on the immunological lateral flow test Singlepath ${ }^{\circledR}$ Salmonella test kit were sent for identification by the MALDI-TOF Biotyper. Out of 147 presumptive ESBL-producing Salmonella spp. isolated from all matrices, 134 (91.2\%) isolates were identified as Salmonella spp. Soil displayed the highest number of isolates identified as Salmonella spp. [47.0\% (63/134)], followed by manure [30.4\% (48/134)], irrigation water [9.7\% (13/134)] and lastly nearby freshwater stream with 7.5\% (10/134). The remaining identified bacterial species included Escherichia coli (5), Pseudomonas putida (3), Pseudomonas monteilii (2), Pseudomonas fulva (1) and Stenotrophomonas maltophilia (Pseudomonas hibiscicola) (2).

\subsection{Serotyping of ESBL-Producing Salmonella spp. Isolates}

Out of 134 [soil $(n=63)$, manure $(n=48)$, irrigation water $(n=13)$ and freshwater stream $(n=10)$ ] confirmed ESBL-producing Salmonella spp. isolates, 129 isolates were successfully serogrouped, representing all available serogroup types (A, B, C, D, Vi-antigen and E or G serogroups). The highest number of isolated ESBL-producing Salmonella spp. belonged to serogroup $\mathrm{C}$, while the lowest was Vi-antigen, with one occurrence in irrigation water. The serogroup A was found in soil $(n=12)$, 
manure $(n=0)$, irrigation water $(n=1)$ and freshwater stream $(n=3)$. The serogroup B was found in soil $(n=15)$, manure $(n=14)$, irrigation water $(n=11)$ and freshwater stream $(n=0)$. Serogroup C was found in soil $(n=21)$, manure $(n=18)$, irrigation water $(n=0)$ and freshwater stream $(n=5)$. Serogroup D was found in soil $(n=13)$, manure $(n=3)$, irrigation water $(n=1)$ and freshwater stream $(n=2)$. Serogroup $\mathrm{E}$ or $\mathrm{G}$ was found in soil $(n=1)$, manure $(n=9)$, irrigation water $(n=0)$ and freshwater stream $(n=0)$.

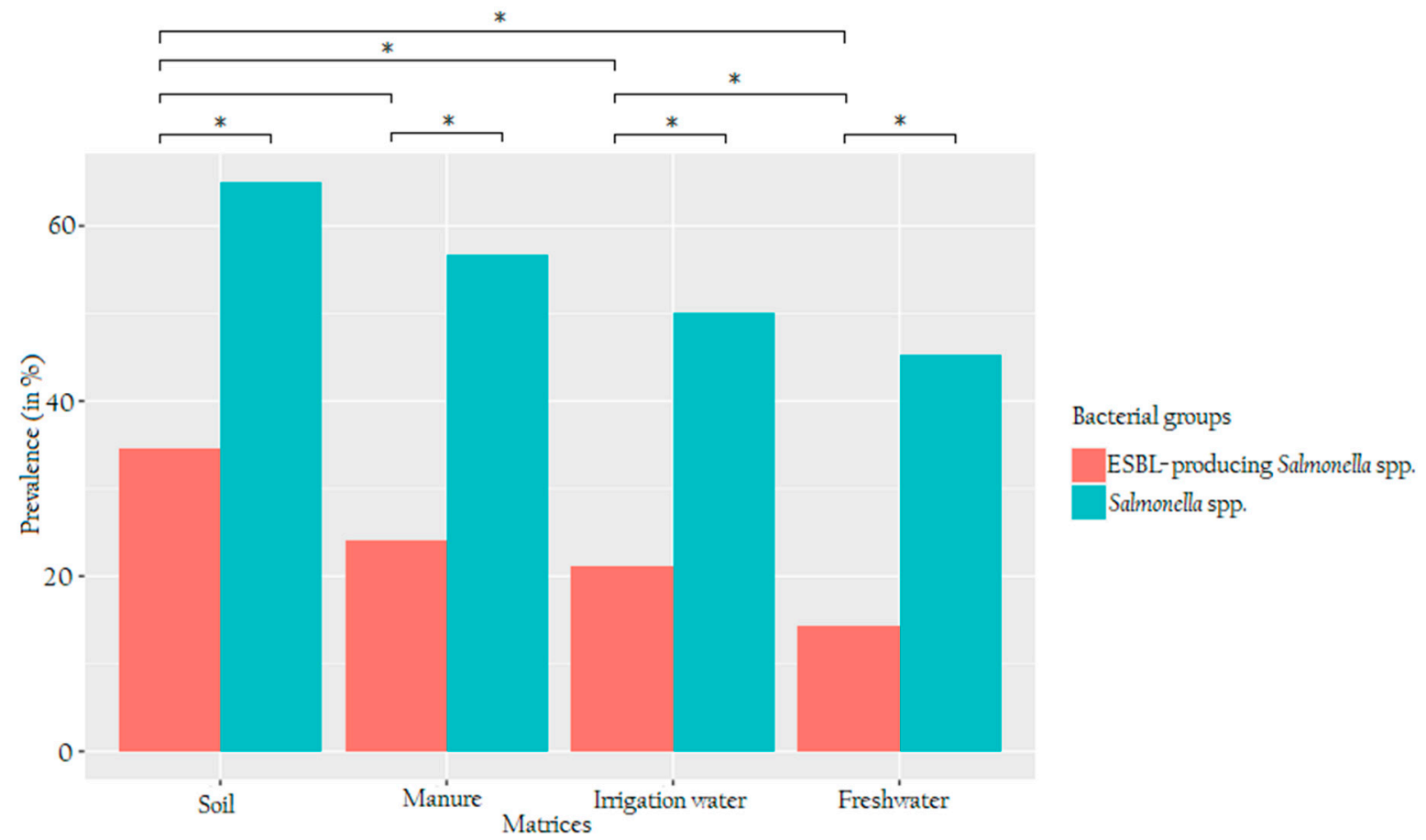

Figure 1. A clustered barplot showing the prevalence of presumptive total and extended-spectrum $\beta$-lactamase (ESBL)-producing Salmonella spp. The red bars represent the prevalence of ESBL-producing Salmonella spp., while the turquoise bars represent total Salmonella spp. from different assessed matrices. The $\mathrm{X}$-axis shows the four sampled environmental matrices, whereas the Y-axis shows the prevalence (in \%) of total and ESBL-producing Salmonella spp. The asterisks denote significant differences between bacterial groups.

\subsection{Detection of ARG in ESBL-Producing Salmonella spp.}

The distribution of selected ARG in ESBL-producing Salmonella spp. assessed in this study is illustrated in Figure 2. Overall, the most commonly detected ARG was bla OXA [75\% (30/40)] in

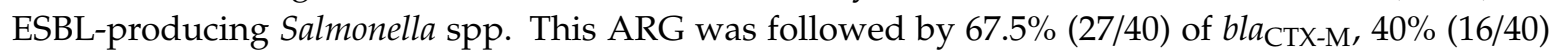
of bla $a_{\text {TEM }}$ and 30\% (12/40) sul1 genes. Nine ESBL-producing Salmonella spp. isolates from soil and manure carried both $b l a_{\mathrm{CTX}-\mathrm{M}}$ and $b l a_{\mathrm{OXA}}$, whereas isolates from both irrigation water and nearby freshwater streams displayed each eight detections for bla $a_{\mathrm{OXA}}$. No isolate carried bla $a_{\mathrm{SHV}}$ from all of the assessed matrices.

\subsection{Detection of VF in ESBL-Producing Salmonella spp.}

The prevalence of VF in the 40 randomly (10 for each matrix) selected ESBL-resistant Salmonella spp. isolates is displayed in Figure 3. Among the five VF, only spaM and orfL were commonly detected in isolates that originated from agricultural settings and the nearby water source. The VF spaM in ESBL-resistant Salmonella spp. isolates from soil was detected at a rate of $50 \%$ and in irrigation water, the rate was $10 \%$, while manure and nearby water displayed a similar rate of $20 \%$. For orfL, ESBL-producing Salmonella spp. isolates, which originated from irrigation water and nearby water 
sources harboured a similar rate of $50 \%$ and those from manure and soil exhibited rates of $40 \%$ and $20 \%$, respectively.

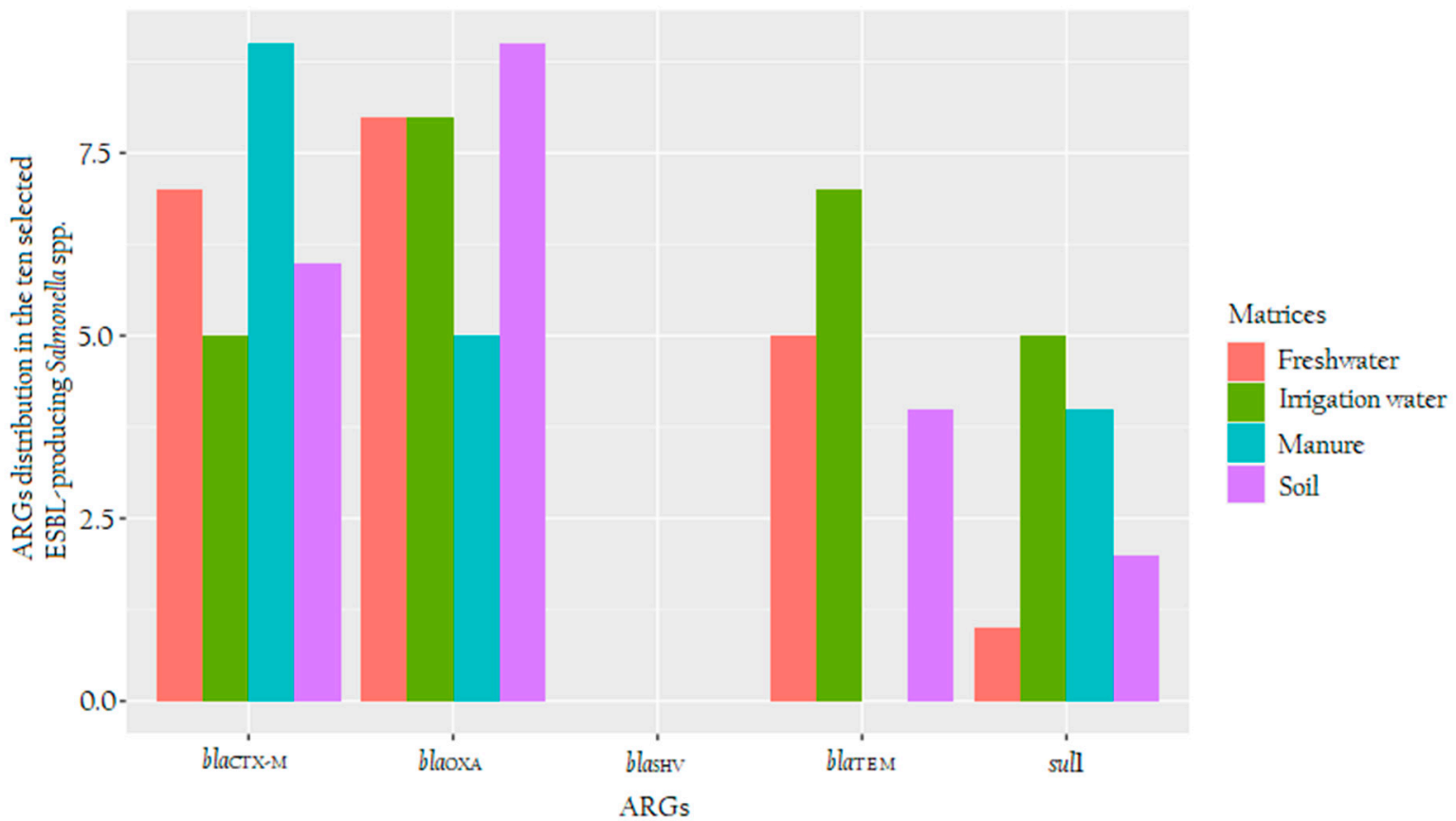

Figure 2. A clustered barplot showing the distribution of antibiotic-resistant genes (ARGs) detected in the ten randomly selected ESBL-producing Salmonella spp. from soil (purple), manure (turquoise), irrigation water (green) and nearby freshwater (red). The X-axis shows the five targeted ARGs, whereas the Y-axis shows the number of ARGs found in each assessed matrix.

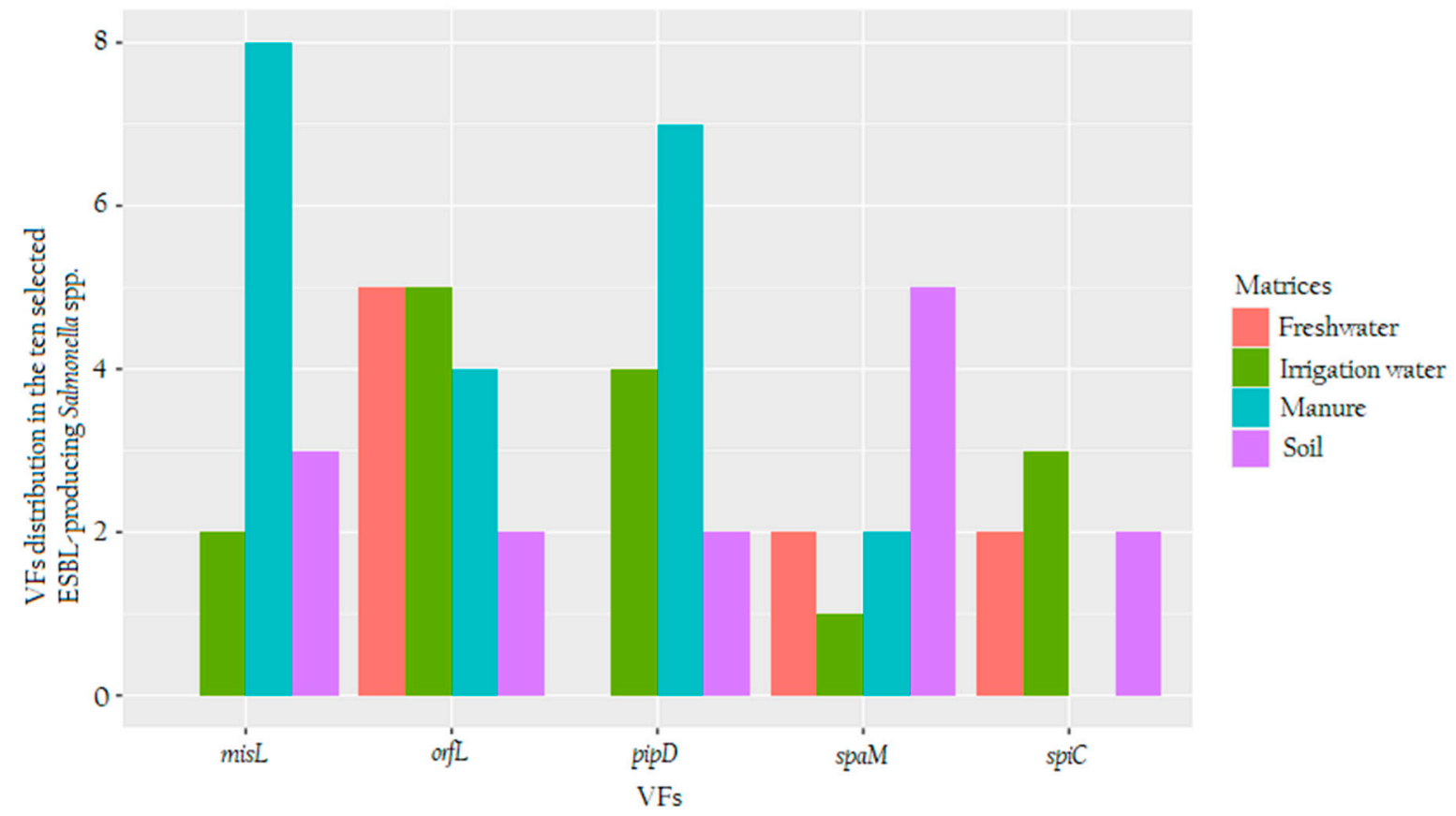

Figure 3. A clustered barplot showing the distribution of virulence factors (VFs) detected in the ten randomly selected ESBL-producing Salmonella spp. from soil (purple), manure (turquoise), irrigation water (green) and nearby freshwater (red). The X-axis shows the five targeted VFs, whereas the Y-axis shows the number of ARGs found in each assessed matrix. 
Two VF-misL and pipD—were detected in ESBL-producing Salmonella spp. isolates from all selected the selected matrices, except for nearby water sources. The highest rate of misL was found in isolates from manure ( $80 \%$ ), followed by those from soil (30) and irrigation water (20\%). PipD VF was detected in isolates from manure at a rate of $70 \%$, from irrigation water and soil at rates of $40 \%$ and 20\%, respectively. The ESBL-resistant Salmonella spp. isolates from soil and manure were found to carry spiC VF at a similar rate of 5\% and those from irrigation water at a rate of $7.5 \%$, while this VF was not detected in manure water. Overall, soil and irrigation water were the only agricultural setting that had ESBL-producing Salmonella spp. isolates that harboured all five VF in this study. Manure and nearby water strains harboured four and three VFs (Figure 3), respectively.

\subsection{InvA Amplicon Analysis}

Eight pooled samples per matrix were sequenced using an Illumina MiSeq platform that generated more than $99.8 \mathrm{Mb}$ of unzipped data for processing using Kaiju for taxonomic identification at serovars level.

Several subspecies and serovars were assigned as Salmonella enterica. Overall, the two species of Salmonella, which are S. enterica and S. bongori, were found with enterica subspecies and diverse serovars. The results showed that the most abundant serovar was $S$. enterica subsp. enterica serovar Heidelberg $(n=136)$, followed by $S$. enterica subsp. enterica serovar Enteritidis $(n=86)$, Newport $(n=68)$, Agona $(n=46)$, Typhimurium $(n=34)$ and Montevideo $(n=20)$ (Figure 4$)$.

To support Figure 4 and statistically approve the differences observed, serovar richness and Shannon-Wiener $\left(\mathrm{H}^{\prime}\right)$ tests were conducted. The serovar richness test revealed that the soil matrix was the richest (81 serovars), followed by manure (61 serovars) and irrigation water (12 serovars) and the least rich was nearby water sources (nine serovars). The significant differences assessed using the one-way ANOVA revealed a significant adjusted $p$-value of $1.17 \times 10^{-6}(p \leq 0.05)$ across all matrices. However, multiple comparisons among the assessed matrices using the Tukey HSD post-hoc revealed that only significant differences between soil-irrigation water $\left(p=5.54 \times 10^{-5}\right)$, soil-nearby water $\left(p=4.21 \times 10^{-5}\right)$, manure-irrigation water $\left(p=8.62 \times 10^{-3}\right)$ and manure-nearby water $\left(p=7.04 \times 10^{-3}\right)$. Soil-manure $(p=0.55)$ and irrigation-water-nearby freshwater $(p=0.99)$ combinations were not statistically different.

As shown in Figure 4A, the soil matrix appeared to have the highest diversity with 81 different serovars. Of these serovars, the most dominant serovars were Salmonella enterica subsp. enterica serovar Heidelberg with $17 \%$, followed by $11 \%$ of S. enterica subsp. enterica serovar Enteritidis, $8 \%$ Newport, 7\% Agona, 4\% Typhimurium, 3\% Montevideo and 1\%-2\% of other serovars. The 81 Salmonella spp. consisted of Salmonella bongori, S. enterica subsp. arizonae, S. enterica subsp. diarizonae, S. Adelaide, Agona, Alachua, Anatum, Baildon, Bareilly, Berta, Blegdam, Bovismorbificans, Braenderup, Cerro, Choleraesuis, Cubana, Derby, Dublin, Eastbourne, Enteritidis, Gallinarum, Gallinarum, Gaminara, Give, Hadar, Hartford, Havana, Heidelberg, Houtenae, Hvittingfoss, Indica, Infantis, Inverness, Java, Javiana Johannesburg, Kentucky, London, Manhattan, Mbandaka, Meleagridis, Minnesota, Mississippi, Montevideo, Moscow, Muenchen, Muenster, Nchanga, Newport, Nitra, Norwich, Ohio, Oranienburg, Paratyphi A, Paratyphi B, Paratyphi C, Pullorum, Rissen, Rough, Rubislaw, Saintpaul, Schwarzengrund, Salamae, Senftenberg, Soerenga, Stanley Tallahassee, Tennessee, Typhi, Typhimurium, Uganda, Urbana, Virchow, Wandsworth, Weltevreden, Weslaco and Worthington.

For manure samples (Figure 4B), the most dominant strain was also S. Heidelberg with $18 \%$, followed by 11\% Enteritidis, 10\% Newport, 5\% Agona, 4\% Typhimurium, 3\% Senftenberg and 1\%-2\% of other serovars. In total, 68 serovars were found in manure samples. These strains included S. bongori, S. enterica subsp. arizonae, diarizonae, enterica, S. enterica subsp. serovars Adelaide, Agona, Alachua, Anatum, Apapa, Aqua, Baildon, Bareilly, Bovismorbificans, Braenderup, Cerro, Choleraesuis, Cubana, Derby, Dublin, Eastbourne, Enteritidis, Gallinarum, Gaminara, Give, Havana, Heidelberg, Houtenae, Infantis, Inverness, Johannesburg, Kentucky, London, Manhattan, Mele, Milwaukee, Minnesota, Mississippi, Montevideo, Muenchen, Nchanga, Newport, Norwich, Oranienburg, Paratyphi, Paratyphi A, Paratyphi B, Paratyphi C, Pullorum, Risse, Rubislaw, Saintpaul, Salamae, Senftenberg, Stanley, 
Tallahassee, Tennessee, Thampson, Typhi, Typhimurium, Uganda, Urbana, Virchow, Wandsworth, Weltevreden and Worthington.

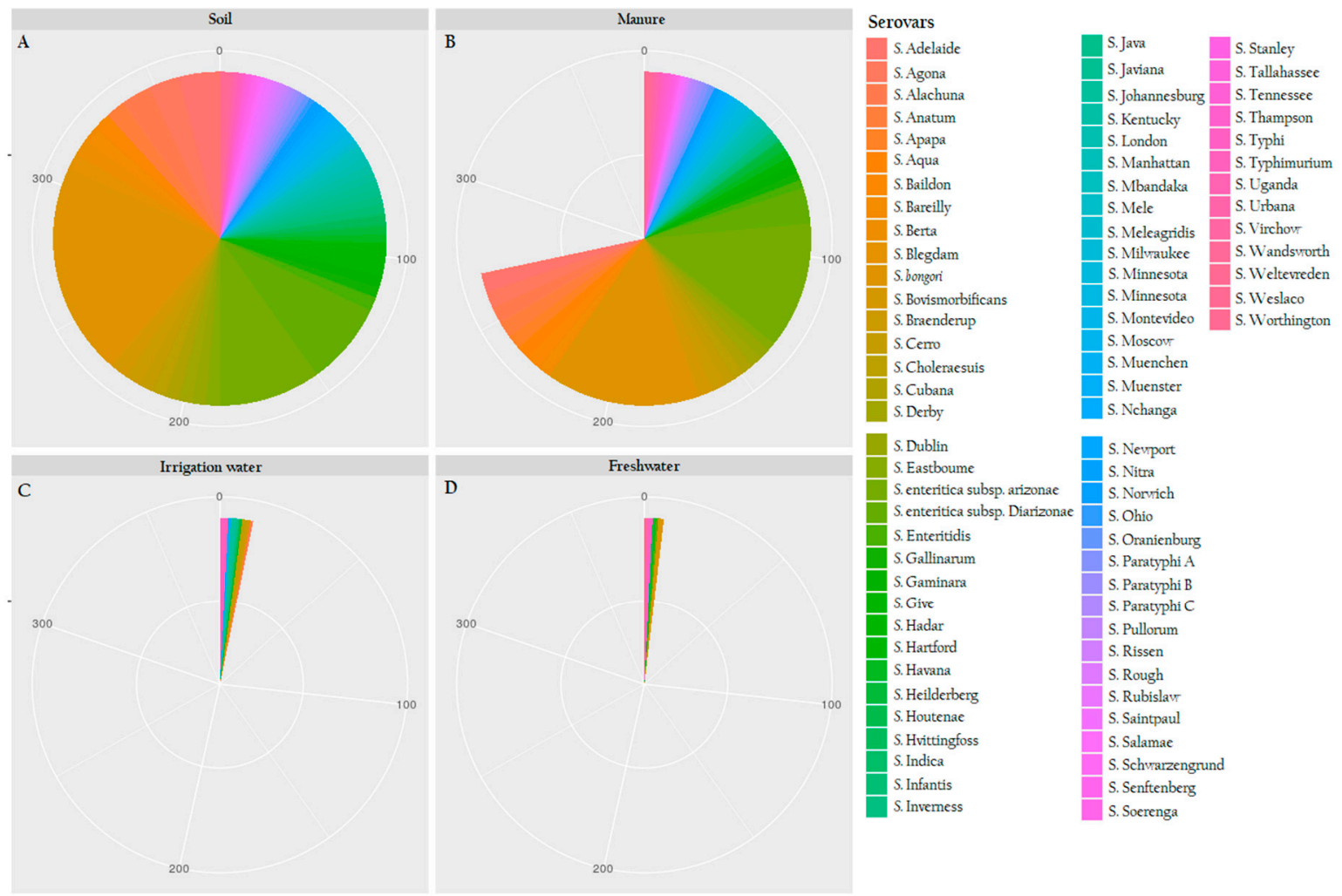

Figure 4. Pie charts showing diversity analysis of ESBL-producing Salmonella spp. from (A) soil matrix with 81 serovars, and dominant serovars were Salmonella enterica subsp. enterica serovar Heidelberg with $17 \%$, followed by $11 \%$ of S. enterica subsp. enterica serovar Enteritidis, $8 \%$ Newport, $7 \%$ Agona, $4 \%$ Typhimurium, $3 \%$ Montevideo and $1 \%-2 \%$ of other serovars; (B) manure matrix with 68 serovars, and dominant serovars were $S$. Heidelberg with $18 \%$, followed by $11 \%$ Enteritidis, $10 \%$ Newport, $5 \%$ Agona, 4\% Typhimurium, 3\% Senftenberg and 1\%-2\% of other serovars; (C) irrigation water with 12 serovars, and dominant serovars were $17 \%$ of $S$. Typhimurium, followed by $11 \%$ of $S$. Johannesburg and S. Heidelburg; and (D) freshwater stream with 9 serovars and the most abundant was Salmonella enterica subsp. enterica (19\%).

Unlike soil and manure samples, irrigation water had low diversity (Figure 4C), with S. Typhimurium being the most abundant (17\%), followed by $11 \%$ of $S$. Johannesburg, S. Heidelburg, S. enterica subsp. enterica. In addition, the following species and subspecies accounted for $5 \%$ to $6 \%$ of the diversity of irrigation samples: Salmonella enterica, Salmonella enterica subsp. enterica, Salmonella enterica subsp. enterica serovars Typhimurium, Johannesburg, Heidelberg, Newport, Inverness, Gallinarum, Choleraesuis, Cerro, Bovismorbificans and Alachua.

Similar to irrigation water, freshwater samples had low Salmonella diversity (Figure 4D), of which the most abundant was Salmonella enterica subsp. enterica (19\%), followed by Salmonella enterica $(18 \%)$ and other isolates serovars accounted for $9 \%$ of the total population. The following species and subspecies were found: S. bongori, S. enterica subsp. enterica serovars Weltevreden, Enteritidis, Typhimurium, Typhi, Heidelberg and Bovismorbificans.

To assess the shared ESBL-producing Salmonella spp. serovars across all sampled matrices, a Venn diagram was built (Figure 5). Numbers inside shared intersecting circles, which represent the number of shared serovars in soil, manure, irrigation water and freshwater stream environment. The four environments shared five serovars. Twelve serovars were shared between soil and manure. Irrigation and freshwater shared five serovars. 


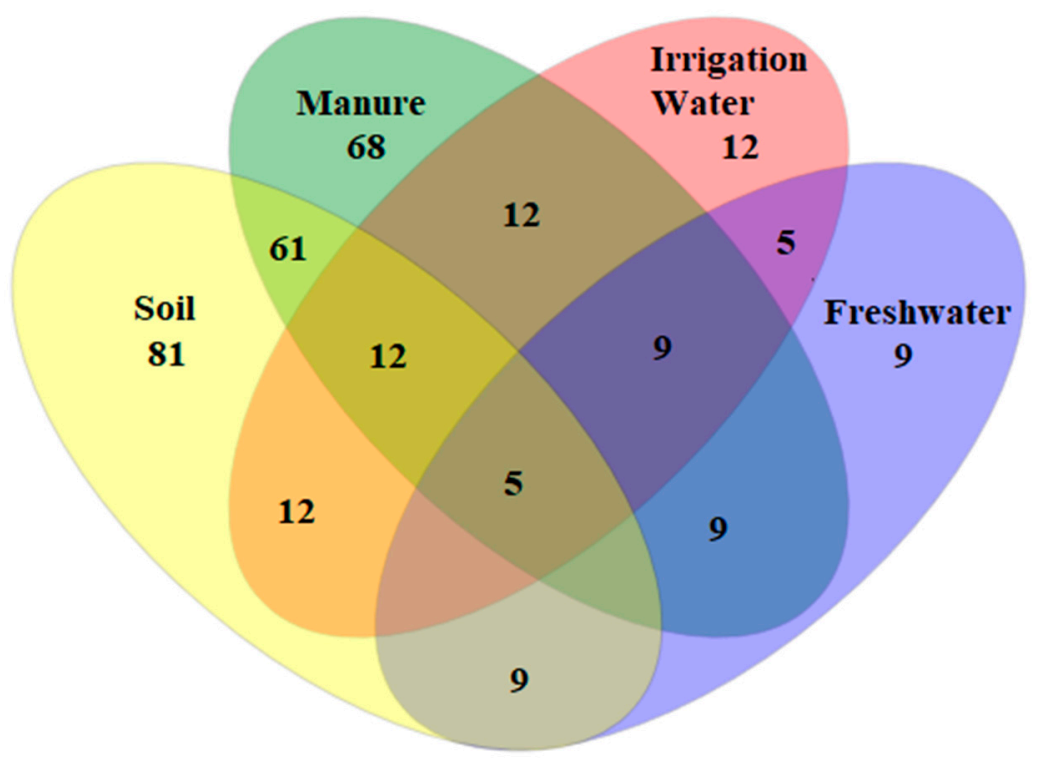

Figure 5. A Venn diagram depicts the overlap (or shared) ESBL-producing Salmonella spp. serovars in a multidimensional network between soil, manure, irrigation water and freshwater matrices. The number inside overlapping ellipses denotes shared serovars.

\section{Discussion}

Worldwide, there has been an increase in reports of ESBLs-producing Salmonella spp., including Central Europe [41], South, Eastern and Western Asia [42], North America [43] and South and North Africa [44]. Although the presence of ESBL-producing Salmonella spp. has become a great public health concern worldwide [45], studies linking environment to the clinical occurrence of ESBL-producing Salmonella are still few, especially in South Africa. It is, therefore, important to track the prevalence, dissemination and diversity of Salmonella from agricultural environments to the aquatic environment, which is used in the developing world for drinking and recreational purposes. Thus, this study was conducted to uncover the diversity and related strains of ESBL-producing Salmonella between agricultural settings (soil, manure and irrigation water) and a nearby freshwater stream. Due to various limitations associated with culture-based methods [46-48], in this study, we employed both culture-dependent and independent methods to investigate the dissemination of ESBL-producing Salmonella spp. from agricultural to aquatic environments.

Using CHROMagar ${ }^{\mathrm{TM}}$ Salmonella Plus media and CHROMagar ${ }^{\mathrm{TM}}$ Salmonella Plus media supplemented with CHROMagar ${ }^{\mathrm{TM}}$ ESBL Supplement, results of the present study revealed the prevalence of Salmonella spp. and ESBL-producing Salmonella spp. from both agricultural matrixes (soil, manure, irrigation water) and freshwater stream samples. The highest prevalence of Salmonella spp. $(62.5 \%, 65 / 104)$ and ESBL-producing Salmonella $(34.6 \%, 36 / 104)$ isolates were detected in soil samples as compared to other sample matrices. This might be due to factors such as temperature, moisture, soil type, UV light and soil organisms that contribute to the survival of Salmonella [49] or the fact that the soil acts as a recipient of all contaminated sources during the farming process. Although the manure applied for soil fertility and the stored-dam water used for irrigation were also found to be contaminated with both Salmonella spp. and ESBL-producing Salmonella, a gradual decrease in the prevalence of these organisms was observed from soil to nearby water sources (Figure 1). Our findings corroborate those of Adzitey et al. [50], who also highlighted that only 12 out of 275 different drinking water samples tested positive for Salmonella spp. Furthermore, the findings of the present study revealed that the prevalence of Salmonella spp. was significantly higher than that of ESBL-producing Salmonella in all four matrices (1.80 to 3.13 fold) during the sampling regime (from June to September 2018). These findings also agree with previous investigators who reported 
that the prevalence of ESBL-producing Salmonella varied in different provinces, sampling years and sampling seasons [51].

During the study period, MALDI-TOF Biotyper was used for the identification of Salmonella spp. and ESBL-producing Salmonella spp. isolates, as it provides high accuracy in species-level identification [52]. Previous investigators have also used this method to identify and discriminate Salmonella spp. from other species. Out of 147 isolates obtained from all matrices, $134(91.2 \%)$ isolates were identified as Salmonella spp. In addition to this bacterium, other species such as E. coli, Pseudomonas putida, Pseudomonas fulva and Stenotrophomonas maltophilia (Pseudomonas hibiscicola) were also identified. The detection of these species might be due to environmental complexity and the fitness of the environment. Except for Vi-antigen, all the serogroups (A, B, C, D, E or G) were found in ESBL-producing Salmonella spp. isolated from soil, with the serogroups $C$ reflecting as the highest serogroup $(n=21)$ and $\mathrm{E}$ or $\mathrm{G}$ as the lower $(n=1)$. Although manure isolates harboured four serogroups (B, C, D, E or G), with serogroup C $(n=18)$ being the most identified, no serogroups with A and Vi-antigen were found. Despite its predominance in all isolates of the matrixes in this study, serogroup $C$ was not found in irrigation water isolates.

Nevertheless, one isolate from this type of water exceptionally harboured the Vi-antigen that was not identified in other matrix isolates. In this study, freshwater harboured only three types of serogroups (A, C and D). Overall, the findings of this study showed that ESBL-producing Salmonella isolates were successfully serogrouped, and the majority of isolates belonged to serogroup C. A previous study that focused on poultry isolates also reported that $97 \%$ of the isolates belonged to serogroups B, C1 and C2 [53]. Roy et al. [54] also found that the majority of poultry (95\%) harboured Salmonella isolates, which belonged to serogroups $B$ and $C$. These findings have shown that serogroup $C$ remains the most predominant in agricultural settings. Our findings are in agreement with previous studies, which revealed serogroup $C$ as the most prevalent serogroup and suggested that strains within this serogroup are multidrug-resistant, as reported elsewhere [55-57].

To assess the genetic attributes behind the observed resistivity, molecular characterisation was done, and the presence of resistant genes such as $b l a_{\mathrm{OXA}}, b l a_{\mathrm{TEM}}, b l a_{\mathrm{SHV}}, b l a_{\mathrm{CTX}-\mathrm{M}}$ and one gene that encodes for the resistance to sulphonamides (sul1) were ascertained. Overall, bla OXA gene was found to be the most commonly detected ARG (75\%) in all ESBL-producing Salmonella spp. isolates from all the matrices, while no isolates carried bla $a_{\mathrm{SHV}}$. It was also noted that the soil isolates did not harbour $b l a_{\mathrm{TEM}}$ (Figure 2). Previous studies have implicated genes such as $b l a_{\mathrm{TEM}}$ and $b l a_{\mathrm{CTX}-\mathrm{M}}$ as responsible for the appearance of resistance to third-generation cephalosporins $[58,59]$.

Moreover, the sul1 gene has been detected in most Salmonella isolates that exhibit resistance to trimethoprim-sulfamethoxazole and $b l a_{\mathrm{TEM}}$, and $b l a_{\mathrm{OXA}}$ genes have been described as the enzymes most frequently related to ampicillin and amoxicillin/clavulanate resistance [60]. Binh et al. [61] detected the abundance of the resistance genes sul1, sul 2 and $b l a_{\text {TEM }}$ in field-scale manures. Another study reported sul1 as the predominant gene in S. Typhimurium [62]. Soil isolates have been shown to have a high diversity of ARG. Our findings were found to be similar to Durso et al. [63] and Nesme et al. [64], where metagenomic data analyses suggest that the soil has a high diversity of ARG. The fact that manure and irrigation water are used in agriculture to enhance the fertility of the soil and the growth of crops means these factors could influence the diversity of ARG in soil. The bla $a_{\text {TEM }}$ was consistently present in soil, irrigation water and freshwater samples, but not in the manure samples. The first report of the occurrence of the bla $a_{\text {TEM }}$ gene in Salmonella recovered from animal faeces was identified in the Eastern Cape province of South Africa [65]. It should be mentioned that the presence of antibiotics, antibiotic-resistant bacteria (ARB) and ARG have been detected in numerous rivers worldwide [66]. Among the genes, $\beta$-lactamases were also reported, e.g., $b l a_{\mathrm{CTX}-\mathrm{M}}, b l a_{\mathrm{IMP}}, b l a_{\mathrm{VIM}}, b l a_{\mathrm{KPC}}$ and variants of these genes may encode ESBL or carbapenemase activity [67]. In this study, a low number of ARG were noted in freshwater stream samples. According to Foote et al. [68], low concentrations of ARG and ARB in large freshwater streams might be due to the water current and strong tide. The contamination of ESBL-positive bacteria and associated genes (bla $a_{\mathrm{SHV}}, b l a_{\mathrm{CTX}-\mathrm{M}-15}$ and $\left.b l a_{\mathrm{TEM}}\right)$ have also been observed 
in environmental and drinking water sources in Nigeria [69]. Since rivers and lakes are used as a source of irrigational and recreational purposes [70], the presence of these ARG in water bodies represents a public health concern. Other study revealed the presence of $b l a_{\mathrm{TEM}-1}$ and $b l a_{\mathrm{CTX}-\mathrm{M}}$ genes in the same genetic environment in clinical Enterobacteriaceae isolates, producing bla ${ }_{\mathrm{CTX}-\mathrm{M}-1}$ type $\beta$-lactamases [71].

In this study, we also assessed virulence genes such as spiC, pipD, spaM, orfL and misL genes. The orfL and misL genes have been reported to be responsible for the survival of Salmonella in host macrophages. The orfL gene is also involved in adhesion, autotransportation and colonisation and is found in SPI-4 [72]. The pipD gene is a type III secreted effector associated with the SPI-1 system and is found in SPI-5 [72]. When assessing the virulence profiles of isolated ESBL-producing Salmonella spp., the most commonly detected VF was orfL in $40.0 \%$ (16/40) of ESBL-producing Salmonella spp. This VF was followed by misL in 32.5\% (13/40), pipD in 30.0\% (12/40), spaM in 25.0\% (10/40) and the lowest was spiC in 17.5\% (7/40). Our findings differ from those of Zishiri et al. [27], who reported the virulence genes isolated from South African clinic isolates that harboured $85 \%$ of spiC gene, followed by the pip $\mathrm{D}$ $(80 \%)$, then $\operatorname{misL}(75 \%)$ and finally $20 \%$ of orf L genes. The reason might be due to the fact that our isolates were recovered from agricultural environments. It should be noted that the presence of the virulence gene in the majority of agricultural isolates highlights the role of this virulence gene in the production of enterotoxin, which is responsible for causing acute gastroenteritis. Thus, the study of virulence genes spreading in different Salmonella isolates would contribute to a better understanding of Salmonella pathogenicity.

The presence of the VF described above was frequently associated with the invA gene. This gene is found in SPI-1 and is vital because it is conserved in all Salmonella and is well-known as invasion gene $\mathrm{A}(\mathrm{inv} A)$, which is responsible for host invasion [73]. Although reported not to be present in all Salmonella spp., it has been established by the U.S. Food and Drug Administration as a confirmatory gene for pathogenic Salmonella spp. [74]. Furthermore, as highlighted above, it possesses the ability to reveal up to 86 serovars [31]. However, in this study, all suspected ESBL-producing Salmonella spp. isolates grown on ESBL-supplemented CHROMagar ${ }^{\mathrm{TM}}$ Salmonella Plus plates were positive for the invA gene. These findings are in agreement with a previous study conducted by Arafat et al. [75], which showed that all isolates possessed the inv A gene. However, results from Kadry et al. [30] revealed that in eight Salmonella isolates, only 50\% were positive for invA gene in both egg (S. Typhimurium) and human (S. Virchow and $S$. Kentucky) isolates. To the best of our knowledge, there is a paucity of studies revealing the VF harboured in Salmonella spp. isolated from agricultural environments.

In this study, we found 81, 68, 12 and 9 ESBL-producing Salmonella spp. serovars from soil, manure, irrigation water and nearby freshwater, respectively. Soil was shown to have an abundant number of serovars as compared to other matrices. We found that five Salmonella spp. serovars were shared among soil, manure, irrigation water and nearby water sources. Interestingly, soil and manure shared more Salmonella spp. serovars $(n=61)$, while irrigation water and freshwater $(n=5)$ and soil and irrigation water $(n=12)$ shared the same number of serovars (Figure 5). However, there were 19 and 7 unique ESBL-resistant Salmonella serovars found in soil and manure, respectively. Notably, all irrigation water and freshwater Salmonella serovars were found in both soil and manure samples. One explanation for the lower occurrence of ESBL-producing Salmonella spp. in irrigation water and freshwater might be to the matrix physical state as microorganisms tend to be unevenly distributed, unlike in a solid matrix. The presence of all certain serovars from soil and manure samples found in freshwater might be due to agricultural runoff during heavy rains. In contrast, the presence of all irrigation water Salmonella spp. in soil could indicate how untreated wastewater used as irrigation water might pollute the receiving soil.

Overall, we found two species of Salmonella, which are S. enterica and S. bongori with the diverse S. enterica subspecies and serovars (Figure 4). In the United States and Canada, S. Heidelberg was frequently isolated from clinical salmonellosis cases, retail meats and livestock serotype [76]. These results were similar to our findings, where the most abundant serovar was $S$. Heidelberg. However, from 1996 to 2006, South Africa veterinary diagnostic laboratory data revealed that the most 
common Salmonella serovars were S. Typhimurium, Enteritidis, Isangi, Infantis, Dublin, Heidelberg, Virchow, Newport, Muenchen, Hadar, Anatum, Arizonae and Schwarzengrund [77]. Salmonella species with various serovars, S. Typhi, the highest at 69/119 (57.9\%), followed by serovar Typhimurium at 28/119 (23.5\%) were serotyped from a tertiary hospital in Eastern Cape, South Africa [78]. Studies have shown the presence of a large diversity of different serovars in the aquatic environments [79]. In Ouagadougou, 22 different serotypes were isolated from surface water [80]. These serovars imply that other external factors may also play an important role in AR dissemination.

\section{Conclusions}

To the best of our knowledge, this study represents one of the few reports investigating the dissemination of ESBL-producing Salmonella spp. from agricultural to aquatic environments using a Pretoria North farm as a case study. This study provides valuable information on the antibiotic resistance, virulence gene content and serovar diversity in ESBL-producing Salmonella isolated from soil, manure, irrigation water and freshwater stream samples. The high rate of ESBL-producing Salmonella species was revealed, but the molecular investigation also determined the presence of sul1 genes associated with virulence factors. The most common resistant gene was bla $a_{\mathrm{OXA}}$, followed by $b l a_{\mathrm{CTX}}, b l a_{\mathrm{TEM}}$ and lastly sul1. Bla $a_{\mathrm{SHV}}$ was not detected in all assessed matrices. Soil was shown to have high diversity and is presented as a major reservoir of ESBL-producing Salmonella sp. Our findings conclude that agricultural environment contamination may have a direct relationship with the presence of antibiotic-resistant Salmonella in freshwater stream samples. The presence of ESBL-producing Salmonella in freshwater stream samples is a potential health risk. To overcome the dissemination of ARB and ARG from agricultural environments, antimicrobial resistance surveillance needs to be implemented in agricultural environments to reduce the dissemination of ESBL-producing Salmonella to aquatic environments.

Author Contributions: Conceptualisation: M.D.E. and M.N.B.M.; Data curation: C.M.R.; Formal analysis: C.M.R.; Funding acquisition: M.N.B.M.; Investigation: C.M.R.; Methodology: C.M.R. and M.D.E.; Project administration: M.N.B.M.; Resources: M.N.B.M.; Software: C.M.R. and M.D.E.; Supervision: M.N.B.M.; Validation: M.D.E.; Visualisation: M.D.E; Writing—original draft: C.M.R. and M.D.E.; Writing—review and editing: M.N.B.M. All authors have read and agreed to the published version of the manuscript.

Funding: This research article received funding from the National Research Foundation and South African Research Chairs Initiative in Water Quality and Wastewater management [grant number: UID87310]. CMR received an innovation scholarship from National Research Foundation [grant number: UID112459]. Opinions expressed and conclusions arrived at are those of the authors and are not necessarily to be attributed to the funders.

Conflicts of Interest: The authors declare no conflict of interest.

\section{References}

1. Bhatta, D.R.; Bangtrakulnonth, A.; Tishyadhigama, P.; Saroj, S.D.; Bandekar, J.R.; Hendriksen, R.S.; Kapadnis, B.P. Serotyping, PCR, phage-typing and antibiotic sensitivity testing of Salmonella serovars isolated from urban drinking water supply systems of Nepal. Lett. Appl. Microbiol. 2007, 44, 588-594. [CrossRef] [PubMed]

2. Amagliani, G.; Brandi, G.; Schiavano, G.F. Incidence and role of Salmonella in seafood safety. Food Res. Int. 2012, 45, 780-788. [CrossRef]

3. Stanaway, J.D.; Parisi, A.; Sarkar, K.; Blacker, B.F.; Reiner, R.C.; Hay, S.I.; Nixon, M.R.; Dolecek, C.; James, S.L.; Mokdad, A.H.; et al. The global burden of non-typhoidal salmonella invasive disease: A systematic analysis for the Global Burden of Disease Study 2017. Lancet Infect. Dis. 2019, 19, 1312-1324. [CrossRef]

4. Yang, Y.T.; Swinburne, M. New Produce Safety Regulations. Public Health Rep. 2016, 131, 754-757. [CrossRef]

5. Jaja, I.F.; Bhembe, N.L.; Green, E.; Oguttu, J.; Muchenje, V. Molecular characterisation of antibiotic-resistant Salmonella enterica isolates recovered from meat in South Africa. Acta Trop. 2019, 190, 129-136. [CrossRef]

6. Hanning, I.B.; Nutt, J.D.; Ricke, S.C. Salmonellosis Outbreaks in the United States Due to Fresh Produce: Sources and Potential Intervention Measures. Foodborne Pathog. Dis. 2009, 6, 635-648. [CrossRef] 
7. Fearnley, E.; Raupach, J.; Lagala, F.; Cameron, S. Salmonella in chicken meat, eggs and humans; Adelaide, South Australia, 2008. Int. J. Food Microbiol. 2011, 146, 219-227. [CrossRef]

8. M'ikanatha, N.M.; Sandt, C.H.; Localio, A.R.; Tewari, D.; Rankin, S.C.; Whichard, J.M.; Altekruse, S.F.; Lautenbach, E.; Folster, J.P.; Russo, A.; et al. Multidrug-Resistant Salmonella Isolates from Retail Chicken Meat Compared with Human Clinical Isolates. Foodborne Pathog. Dis. 2010, 7, 929-934. [CrossRef]

9. Ifeoma Stella, E. Evaluation of Salmonella Species in Water Sources in Two Local Government Areas of Anambra State. Cohesive J. Microbiol. Infect. Dis. 2018, 1. [CrossRef]

10. Gelband, H.; Molly Miller, P.; Pant, S.; Gandra, S.; Levinson, J.; Barter, D.; White, A.; Laxminarayan, R. The state of the world's antibiotics 2015. Wound Health South. Afr. 2015, 8, 30-34.

11. Akinyemi, K.O.; Iwalokun, B.; Alafe, O.; Mudashiru, S.; Fakorede, C. blaCTX-M-I group extended spectrum beta lactamase-producing Salmonella typhi from hospitalised patients in Lagos, Nigeria. Infect. Drug Resist. 2015, 99. [CrossRef]

12. Marti, E.; Variatza, E.; Balcazar, J.L. The role of aquatic ecosystems as reservoirs of antibiotic resistance. Trends Microbiol. 2014, 22, 36-41. [CrossRef] [PubMed]

13. Martin, M.J.; Thottathil, S.E.; Newman, T.B. Antibiotics Overuse in Animal Agriculture: A Call to Action for Health Care Providers. Am. J. Public Health 2015, 105, 2409-2410. [CrossRef] [PubMed]

14. Choukr-Allah, R. Wastewater Recycling and Reuse in Mediterranean Region as a Potential Resources for Water Saving and Sustainable Agriculture. In Proceedings of the Symposium International" Agriculture Durable en Region Mediterranean (AGDUMED), Rabat, Maroc, 14-16 May 2009; pp. 14-15.

15. Parisi, A.; Crump, J.A.; Glass, K.; Howden, B.P.; Furuya-Kanamori, L.; Vilkins, S.; Gray, D.J.; Kirk, M.D. Health Outcomes from Multidrug-Resistant Salmonella Infections in High-Income Countries: A Systematic Review and Meta-Analysis. Foodborne Pathog. Dis. 2018, 15, 428-436. [CrossRef] [PubMed]

16. World Health Organization. WHO Publishes List of Bacteria for Which New Antibiotics are Urgently Needed; World Health Organization: Geneva, Switzerland, 2017.

17. Nicolau, D.P.; Carmeli, Y.; Crank, C.W.; Goff, D.A.; Graber, C.J.; Lima, A.L.L.; Goldstein, E.J. Carbapenem stewardship: Does ertapenem affect Pseudomonas susceptibility to other carbapenems? A review of the evidence. Int. J. Antimicrob. Agents 2012, 39, 11-15. [CrossRef] [PubMed]

18. Ndugulile, F.; Jureen, R.; Harthug, S.; Urassa, W.; Langeland, N. Extended Spectrum $\beta$-Lactamases among Gram-negative bacteria of nosocomial origin from an Intensive Care Unit of a tertiary health facility in Tanzania. BMC Infect. Dis. 2005, 5, 86. [CrossRef]

19. Seong, W.-J.; Kwon, H.-J.; Kim, T.-E.; Lee, D.-Y.; Park, M.-S.; Kim, J.-H. Molecular serotyping of Salmonella enterica by complete rpoB gene sequencing. J. Microbiol. 2012, 50, 962-969. [CrossRef]

20. Blaak, H.; van Hoek, A.H.A.M.; Veenman, C.; Docters van Leeuwen, A.E.; Lynch, G.; van Overbeek, W.M.; de Roda Husman, A.M. Extended spectrum B-lactamase- and constitutively AmpC-producing Enterobacteriaceae on fresh produce and in the agricultural environment. Int. J. Food Microbiol. 2014, 168-169, 8-16. [CrossRef]

21. Reuland, E.A.; al Naiemi, N.; Raadsen, S.A.; Savelkoul, P.H.M.; Kluytmans, J.A.J.W.; Vandenbroucke-Grauls, C.M.J.E. Prevalence of ESBL-producing Enterobacteriaceae in raw vegetables. Eur. J. Clin. Microbiol. Infect. Dis. 2014, 33, 1843-1846. [CrossRef]

22. Veldman, K.; Kant, A.; Dierikx, C.; van Essen-Zandbergen, A.; Wit, B.; Mevius, D. Enterobacteriaceae resistant to third-generation cephalosporins and quinolones in fresh culinary herbs imported from Southeast Asia. Int. J. Food Microbiol. 2014, 177, 72-77. [CrossRef]

23. Raseala, C.M.; Ekwanzala, M.D.; Momba, M.N.B. Multilocus-based phylogenetic analysis of extended-spectrum beta-lactamase Escherichia coli O157:H7 uncovers related strains between agriculture and nearby water sources. J. Infect. Public Health 2020. [CrossRef] [PubMed]

24. Hasman, H.; Mevius, D.; Veldman, K.; Olesen, I.; Aarestrup, F.M. $\beta$-Lactamases among extended-spectrum $\beta$-lactamase (ESBL)-resistant Salmonella from poultry, poultry products and human patients in The Netherlands. J. Antimicrob. Chemother. 2005, 56, 115-121. [CrossRef] [PubMed]

25. Poppe, C.; Martin, L.; Muckle, A.; Archambault, M.; McEwen, S.; Weir, E. Characterization of antimicrobial resistance of Salmonella Newport isolated from animals, the environment, and animal food products in Canada. Can. J. Vet. Res. 2006, 70, 105. [PubMed]

26. Aarestrup, F.M. Antimicrobial susceptibility and occurrence of resistance genes among Salmonella enterica serovar Weltevreden from different countries. J. Antimicrob. Chemother. 2003, 52, 715-718. [CrossRef] 
27. Zishiri, O.T.; Mkhize, N.; Mukaratirwa, S. Prevalence of virulence and antimicrobial resistance genes in Salmonella spp. isolated from commercial chickens and human clinical isolates from South Africa and Brazil. Onderstepoort J. Vet. Res. 2016, 83. [CrossRef]

28. Fakhr, M.K.; Nolan, L.K.; Logue, C.M. Multilocus Sequence Typing Lacks the Discriminatory Ability of Pulsed-Field Gel Electrophoresis for Typing Salmonella enterica Serovar Typhimurium. J. Clin. Microbiol. 2005, 43, 2215-2219. [CrossRef]

29. Abakpa, G.O.; Umoh, V.J.; Ameh, J.B.; Yakubu, S.E.; Kwaga, J.K.P.; Kamaruzaman, S. Diversity and antimicrobial resistance of Salmonella enterica isolated from fresh produce and environmental samples. Environ. Nanotechnol. Monit. Manag. 2015, 3, 38-46. [CrossRef]

30. Kadry, M.; Nader, S.M.; Dorgham, S.M.; Kandil, M.M. Molecular diversity of the invA gene obtained from human and egg samples. Vet. World 2019, 12, 1033-1038. [CrossRef]

31. Buehler, A.J.; Wiedmann, M.; Kassaify, Z.; Cheng, R.A. Evaluation of invA Diversity among Salmonella Species Suggests Why Some Commercially Available Rapid Detection Kits May Fail To Detect Multiple Salmonella Subspecies and Species. J. Food Prot. 2019, 82, 710-717. [CrossRef]

32. Blankenberg, D.; Gordon, A.; von Kuster, G.; Coraor, N.; Taylor, J.; Nekrutenko, A. Manipulation of FASTQ data with Galaxy. Bioinformatics 2010, 26, 1783-1785. [CrossRef]

33. Andrews, S. FastQC: A Quality Control Tool For High Throughput Sequence Data. 2010; pp. $175-176$. Available online: https://www.bioinformatics.babraham.ac.uk/projects/fastqc/ (accessed on 24 September 2020).

34. Bolger, A.M.; Lohse, M.; Usadel, B. Trimmomatic: A flexible trimmer for Illumina sequence data. Bioinformatics 2014, 30, 2114-2120. [CrossRef] [PubMed]

35. Schmieder, R.; Edwards, R. Quality control and preprocessing of metagenomic datasets. Bioinformatics 2011, 27, 863-864. [CrossRef] [PubMed]

36. Krueger, F. Trim galore. A wrapper tool around Cutadapt and FastQC to consistently apply quality and adapter trimming to FastQ files. Babraham Bioinformatics 2015, 516, 517.

37. Chen, S.; Zhou, Y.; Chen, Y.; Gu, J. fastp: An ultra-fast all-in-one FASTQ preprocessor. Bioinformatics 2018, 34, i884-i890. [CrossRef]

38. Edgar, R.C.; Haas, B.J.; Clemente, J.C.; Quince, C.; Knight, R. UCHIME improves sensitivity and speed of chimera detection. Bioinformatics 2011, 27, 2194-2200. [CrossRef]

39. Schmieder, R.; Edwards, R. Fast Identification and Removal of Sequence Contamination from Genomic and Metagenomic Datasets. PLoS ONE 2011, 6, e17288. [CrossRef]

40. Menzel, P.; Ng, K.L.; Krogh, A. Fast and sensitive taxonomic classification for metagenomics with Kaiju. Nat. Commun. 2016, 7, 11257. [CrossRef]

41. Baraniak, A.; Sadowy, E.; Hryniewicz, W.; Gniadkowski, M. Two Different Extended-Spectrum -Lactamases (ESBLs) in One of the First ESBL-Producing Salmonella Isolates in Poland. J. Clin. Microbiol. 2002, 40, 1095-1097. [CrossRef]

42. Rotimi, V.O.; Jamal, W.; Pal, T.; Sovenned, A.; Albert, M.J. Emergence of CTX-M-15 type extended-spectrum $\beta$-lactamase-producing Salmonella spp. in Kuwait and the United Arab Emirates. J. Med Microbiol. 2008, 57, 881-886. [CrossRef]

43. Sjölund, M.; Yam, J.; Schwenk, J.; Joyce, K.; Medalla, F.; Barzilay, E.; Whichard, J.M. Human Salmonella Infection Yielding CTX-M $\beta$-Lactamase, United States. Emerg. Infect. Dis. 2008, 14, 1957-1959. [CrossRef] [PubMed]

44. Usha, G.; Chunderika, M.; Prashini, M.; Willem, S.A.; Yusuf, E.S. Characterization of extended-spectrum $\beta$-lactamases in Salmonella spp. at a tertiary hospital in Durban, South Africa. Diagn. Microbiol. Infect. Dis. 2008, 62, 86-91. [CrossRef] [PubMed]

45. Yates, C.; Amyes, S. Extended-spectrum $\beta$-lactamases in non-typhoidal Salmonella spp. isolated in the UK are now a reality: Why the late arrival? J. Antimicrob. Chemother. 2005, 56, 262-264. [CrossRef] [PubMed]

46. Zhou, Z.; Raskin, L.; Zilles, J.L. Macrolide Resistance in Microorganisms at Antimicrobial-Free Swine Farms. Appl. Environ. Microbiol. 2009, 75, 5814-5820. [CrossRef] [PubMed]

47. Heuer, H.; Schmitt, H.; Smalla, K. Antibiotic resistance gene spread due to manure application on agricultural fields. Curr. Opin. Microbiol. 2011, 14, 236-243. [CrossRef] [PubMed]

48. Sato, T.; Okubo, T.; Usui, M.; Yokota, S.; Izumiyama, S.; Tamura, Y. Association of Veterinary Third-Generation Cephalosporin Use with the Risk of Emergence of Extended-Spectrum-Cephalosporin Resistance in Escherichia coli from Dairy Cattle in Japan. PLoS ONE 2014, 9, e96101. [CrossRef] [PubMed] 
49. Jacobsen, C.S.; Bech, T.B. Soil survival of Salmonella and transfer to freshwater and fresh produce. Food Res. Int. 2012, 45, 557-566. [CrossRef]

50. Adzitey, F.; Ashiagbor, C.N.K.; Abu, H. Prevalence and antibiotic susceptibility of Salmonella spp. from water sources in Tamale, Ghana. Int. J. One Health 2016, 2, 24-28. [CrossRef]

51. Qiao, J.; Zhang, Q.; Alali, W.Q.; Wang, J.; Meng, L.; Xiao, Y.; Yang, H.; Chen, S.; Cui, S.; Yang, B. Characterization of extended-spectrum $\beta$-lactamases (ESBLs)-producing Salmonella in retail raw chicken carcasses. Int. J. Food Microbiol. 2017, 248, 72-81. [CrossRef]

52. Benagli, C.; Rossi, V.; Dolina, M.; Tonolla, M.; Petrini, O. Matrix-Assisted Laser Desorption Ionization-Time of Flight Mass Spectrometry for the Identification of Clinically Relevant Bacteria. PLoS ONE 2011, 6, e16424. [CrossRef]

53. Abdel-Maksoud, M.; Abdel-Khalek, R.; El-Gendy, A.; Gamal, R.F.; Abdelhady, H.M.; House, B.L. Genetic characterisation of multidrug-resistant Salmonella enterica serotypes isolated from poultry in Cairo, Egypt. Afr. J. Lab. Med. 2015, 4. [CrossRef]

54. Roy, P.; Dhillon, A.S.; Lauerman, L.H.; Schaberg, D.M.; Bandli, D.; Johnson, S. Results of Salmonella isolation from poultry products, poultry, poultry environment, and other characteristics. Avian Dis. 2002, 46, 17-24. [CrossRef]

55. Maraki, S.; Papadakis, I.S. Serotypes and Antimicrobial Resistance of Human Nontyphoidal Isolates of Salmonella enterica from Crete, Greece. Interdiscip. Perspect. Infect. Dis. 2014, 2014, 1-5. [CrossRef] [PubMed]

56. Tadesse, G. Prevalence of human Salmonellosis in Ethiopia: A systematic review and meta-analysis. BMC Infect. Dis. 2014, 14, 88. [CrossRef] [PubMed]

57. Kwambana-Adams, B.; Darboe, S.; Nabwera, H.; Foster-Nyarko, E.; Ikumapayi, U.N.; Secka, O.; Betts, M.; Bradbury, R.; Wegmüller, R.; Lawal, B.; et al. Salmonella Infections in The Gambia, 2005-2015. Clin. Infect. Dis. 2015, 61, S354-S362. [CrossRef]

58. Donaldson, S.C.; Straley, B.A.; Hegde, N.V.; Sawant, A.A.; DebRoy, C.; Jayarao, B.M. Molecular Epidemiology of Ceftiofur-Resistant Escherichia coli Isolates from Dairy Calves. Appl. Environ. Microbiol. 2006, 72, 3940-3948. [CrossRef]

59. Frye, J.G.; Fedorka-Cray, P.J. Prevalence, distribution and characterisation of ceftiofur resistance in Salmonella enterica isolated from animals in the USA from 1999 to 2003. Int. J. Antimicrob. Agents 2007, 30, 134-142. [CrossRef] [PubMed]

60. Guerri, M. Detection of integrons and antibiotic-resistance genes in Salmonella enterica serovar Typhimurium isolates with resistance to ampicillin and variable susceptibility to amoxicillin-clavulanate. Int. J. Antimicrob. Agents 2004, 24, 327-333. [CrossRef]

61. Binh, C.T.T.; Heuer, H.; Gomes, N.C.M.; Kaupenjohann, M.; Smalla, K. Similar bacterial community structure and high abundance of sulfonamide resistance genes in field-scale manures. Manure Manag. Uses Environ. Impacts. Hauppauge: Nova Sci. Publ. 2010, 141-166. Available online: http://www.novapublishers.org/catalog/ downloadOA.php? order $=1 \&$ access $=$ true (accessed on 22 August 2020).

62. Randall, L.P. Antibiotic resistance genes, integrons and multiple antibiotic resistance in thirty-five serotypes of Salmonella enterica isolated from humans and animals in the UK. J. Antimicrob. Chemother. 2004, 53, 208-216. [CrossRef]

63. Durso, L.M.; Miller, D.N.; Wienhold, B.J. Distribution and Quantification of Antibiotic Resistant Genes and Bacteria across Agricultural and Non-Agricultural Metagenomes. PLoS ONE 2012, 7, e48325. [CrossRef] [PubMed]

64. Nesme, J.; Cécillon, S.; Delmont, T.O.; Monier, J.-M.; Vogel, T.M.; Simonet, P. Large-Scale Metagenomic-Based Study of Antibiotic Resistance in the Environment. Curr. Biol. 2014, 24, 1096-1100. [CrossRef] [PubMed]

65. Igbinosa, I.H. Prevalence and detection of antibiotic-resistant determinant in Salmonella isolated from food-producing animals. Trop. Anim. Health Prod. 2015, 47, 37-43. [CrossRef] [PubMed]

66. Jia, S.; Zhang, X.-X.; Miao, Y.; Zhao, Y.; Ye, L.; Li, B.; Zhang, T. Fate of antibiotic resistance genes and their associations with bacterial community in livestock breeding wastewater and its receiving river water. Water Res. 2017. [CrossRef]

67. Falagas, M.E.; Karageorgopoulos, D.E. Extended-spectrum $\beta$-lactamase-producing organisms. J. Hosp. Infect. 2009, 73, 345-354. [CrossRef] 
68. Foote, A.D.; Thomsen, P.F.; Sveegaard, S.; Wahlberg, M.; Kielgast, J.; Kyhn, L.A.; Salling, A.B.; Galatius, A.; Orlando, L.; Gilbert, M.T.P. Investigating the Potential Use of Environmental DNA (eDNA) for Genetic Monitoring of Marine Mammals. PLoS ONE 2012, 7, e41781. [CrossRef]

69. Adelowo, O.O.; Caucci, S.; Banjo, O.A.; Nnanna, O.C.; Awotipe, E.O.; Peters, F.B.; Fagade, O.E.; Berendonk, T.U. Extended Spectrum Beta-Lactamase (ESBL)-producing bacteria isolated from hospital wastewaters, rivers and aquaculture sources in Nigeria. Environ. Sci. Pollut. Res. 2018, 25, 2744-2755. [CrossRef]

70. Liu, J.; Dan, X.; Lu, G.; Shen, J.; Wu, D.; Yan, Z. Investigation of pharmaceutically active compounds in an urban receiving water: Occurrence, fate and environmental risk assessment. Ecotoxicol. Environ. Saf. 2018, 154, 214-220. [CrossRef]

71. Eckert, C.; Gautier, V.; Arlet, G. DNA sequence analysis of the genetic environment of various blaCTX-M genes. J. Antimicrob. Chemother. 2006, 57, 14-23. [CrossRef]

72. Hughes, L.A.; Shopland, S.; Wigley, P.; Bradon, H.; Leatherbarrow, A.H.; Williams, N.J.; Bennett, M.; de Pinna, E.; Lawson, B.; Cunningham, A.A.; et al. Characterisation of Salmonella enterica serotype Typhimurium isolates from wild birds in northern England from 2005-2006. BMC Vet. Res. 2008, 4, 4. [CrossRef]

73. Galán, J.E.; Ginocchio, C.; Costeas, P. Molecular and functional characterisation of the Salmonella invasion gene invA: Homology of InvA to members of a new protein family. J. Bacteriol. 1992, 174, 4338-4349. [CrossRef] [PubMed]

74. Cheng, C.-M.; Lin, W.; Van, K.T.; Phan, L.; Tran, N.N.; Farmer, D. Rapid Detection of Salmonella in Foods Using Real-Time PCR. J. Food Prot. 2008, 71, 2436-2441. [CrossRef] [PubMed]

75. Al Arafat, T.; Mahmud, M.R.; Tanim, M.T.I.; Chowdhury, M.M.K.; Rahaman, M.M.; Rahman, S.R.; Rahman, M.M. Genetic Diversity of Salmonella enterica Strains Isolated from Sewage Samples of Different Hospitals in Bangladesh. Bangladesh J. Microbiol. 2019, 35, 57-60. [CrossRef]

76. Zhao, S.; White, D.G.; Friedman, S.L.; Glenn, A.; Blickenstaff, K.; Ayers, S.L.; Abbott, J.W.; Hall-Robinson, E.; McDermott, P.F. Antimicrobial Resistance in Salmonella enterica Serovar Heidelberg Isolates from Retail Meats, Including poultry, from 2002 to 2006. Appl. Environ. Microbiol. 2008, 74, 6656-6662. [CrossRef] [PubMed]

77. Kidanemariam, A.; Engelbrecht, M.; Picard, J. Retrospective study on the incidence of Salmonella isolations in animals in South Africa, 1996 to 2006. J. South Afr. Vet. Assoc. 2010, 81. [CrossRef] [PubMed]

78. Bisi-Johnson, M.; Obi, C. Detection of Carbapenem Resistance in Salmonella Species from a Tertiary Hospital in Eastern Cape, South Africa. Br. Microbiol. Res. J. 2015, 10, 1-6. [CrossRef]

79. Dekker, D.; Krumkamp, R.; Sarpong, N.; Frickmann, H.; Boahen, K.; Frimpong, M.; Asare, R.; Larbi, R.; Hagen, R.; Poppert, S.; et al. Drinking Water from Dug Wells in Rural Ghana-Salmonella Contamination, Environmental Factors, and Genotypes. Int. J. Environ. Res. Public Health 2015, 12, 3535-3546. [CrossRef]

80. Traoré, O.; Nyholm, O.; Siitonen, A.; Bonkoungou, I.J.O.; Traoré, A.S.; Barro, N.; Haukka, K. Prevalence and diversity of Salmonella enterica in water, fish and lettuce in Ouagadougou, Burkina Faso. BMC Microbiol. 2015, 15, 151. [CrossRef]

Publisher's Note: MDPI stays neutral with regard to jurisdictional claims in published maps and institutional affiliations.

(C) 2020 by the authors. Licensee MDPI, Basel, Switzerland. This article is an open access article distributed under the terms and conditions of the Creative Commons Attribution (CC BY) license (http://creativecommons.org/licenses/by/4.0/). 